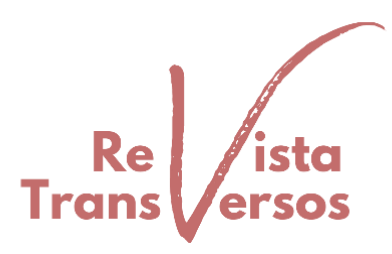

\title{
O FUTURO DO PASSADO: DESAFIOS PARA O ENSINO DA HISTÓRIA NA ESCOLA NUMA PERSPECTIVA GLOBAL
}

\author{
Guilherme Moerbeck \\ Universidade do Estado do Rio de Janeiro \\ guilherme.gomes.moerbeck@uerj.br \\ Marc-André Éthier \\ Université de Montréal \\ marc.andre.ethier@umontreal.ca \\ David Lefrançois \\ Université du Québec en Outaouais \\ david.lefrancois@uqo.ca
}

Desde o final do século XIX, as «revoluções» historiográficas multiplicam-se. Convicções que se estabeleceram a seu tempo como consensos epistemológicos e metodológicos sobre as práticas de investigação neste domínio são substituídas por outras, também aparentemente eternas. Mais recentemente, a reflexão dos historiadores centrou-se mais nos recursos narrativos da escrita da história e nos esforços de descompartimentar, de desconstruir e de problematizar documentos, disciplinas e identidades, mas também sobre a pluralidade das áreas e escalas espaçotemporais a partir das quais se colocam os problemas de investigação. Estas mudanças, tal como as contínuas, são relativas e ocorrem num contexto cultural, econômico, político e social que afeta também o mundo da educação.

Neste contexto, quais desafios se colocam ao ensino escolar da história? Como aproveitar a situação para aumentar a motivação dos alunos, na classe de história, para os tornar mais intelectualmente autônomos e curiosos, para desenvolver o seu pensamento crítico, a sua conscientização?

Esse ensaio inicial tem como intuito levantar algumas questões que deram origem e inspiraram a proposição desse dossiê, além de, evidentemente, apresentar os trabalhos que o compõem. A inspiração inicial é uma reflexão sobre o futuro do passado, talvez nem se precise 
referenciar a quase-explícita menção à obra de R. Koselleck (KOSELLECK, 2006). Tal expressão chama-nos a atenção para uma metáfora. Em seu sentido etimológico, a preposição meta nos convida a pensar naquilo que está no meio de algo ou junto à alguma coisa, algo não facilmente discernível. Como em uma transposição ao sentido temporal, pensa-se no tange à constituição do sentido histórico pelo ser, à atribuição de sentido à própria historicidade, cuja operação é ontológica e determinada pelo tempo em que se vive (RICOEUR, 2000; RÜSEN, 2020). Da atribuição dos sentidos constituídos nas representações mentais de cada um e que são ancoradas em determinados grupos sociais, o fazer a História como empreendimento científico se empenha, via de regra, com unidades de análise maiores, mesmo que o indivíduo lhe sirva de porta ao imaginário de uma época, como o caso de Menocchio e seus inquisidores (GINZBURG, 2002).

Como fora mencionado no primeiro parágrafo, os quadros teóricos que nos permitem tentar capturar o tempo e a ação humana variaram muito desde o século XIX. Assim, um gênero literário, a história, se transforma, se configura em um campo científico. Impossível, mesmo infrutífero querer retomar toda esta trajetória aqui. Seja como for, é importante reconhecer o grande aumento do número de investigações no domínio da história que decorreu da profissionalização deste domínio intelectual. Em consequência, a variabilidade dos temas, as diferentes abordagens teóricas e as metodologias vieram colorir o campo da história acadêmica com grande diversidade - em suma, dessa tão cara dimensão do "homem no tempo", para aludir a outro grande nome da historiografia contemporânea (BLOCH, 2002). Trata-se, portanto, de uma magnífica pulverização de investigações, ora vistas como migalhas (DOSSE, 2003), ora como um impulso a um novo quadro epistemológico que liga a ciência a numerosas exigências que, inevitavelmente, dialogam com exigências sociais, políticas, nesse sentido, fora do domínio científico stricto sensu. Essas reconfigurações do conhecimento histórico, dentro do que se poderia denominar fluxo social das narrativas históricas (CARDOSO, 2019), ou cultura histórica (RÜSEN, 1994), foram levadas a cabo nos debates acadêmicos dos últimos anos, como no caso da História Pública; ou de uma "história profana", do universo quase sem fim do divertimento "histórico", como os filmes, romances, jogos videogames, histórias em quadrinho e assim por diante; além, claro, da história escolar (ÉTHIER; LEFRANÇOIS, 2021).

Todas as formas de divulgação da história, a própria História Pública enquanto disciplina "in fieri", parecem cada vez mais importantes ao diálogo com a História Escolar (WANDERLEY, 2020). Em prolífica entrevista concedida a este dossiê, o professor François 
Audigier afirma que os propósitos da instituição escolar são os de, indissociavelmente, instruir, educar e socializar os alunos. Portanto, crianças e adolescentes que chegam todos os dias à escola relacionam-se com saberes variados oriundos da academia, mas que se encontram, às vezes se chocam, com outras formas de saberes advindos de um mundo assaz polifônico que se utiliza da história a todo momento. Parece provável que os discentes muito já saibam sobre a Grécia Antiga quando encontram-se em uma aula do ensino fundamental pela primeira vez, e põem os olhos sobre um livro didático que contém essa temática como um saber valorizado culturalmente. Algumas aulas de estética da recepção ajudariam aos pesquisadores a entender melhor essas camadas de sentido que se formam na leitura das temporalidades históricas, poder-se-ia dizer nas suas multiformes representações e apropriações do passado. Quando um jovem aluno abre um livro didático no capítulo: "A Grécia Antiga”, qual seria a sua reação? Talvez, seja uma boa pesquisa ainda por se fazer (BAKOGIANNI, 2016; LEITE, 2020; MOERBECK, 2018, 2021). Não está mais lá a estética PlayStation que tanto anima a juventude a assistir filmes como Fúria de Titãs (2010) ou a jogar em rede Assassin 's Creed Odyssey (ÉTHIER; LEFRANÇOIS, 2021; NETO, 2019). Ademais, o livro didático, privado dos efeitos digitais, apresenta aos alunos uma espécie de narrativa cujo "referente é consensual". Dito de outra maneira, isto é, trata-se de debates que silenciam em função de um fio discursivo que parece, tout court, sem problemas ou dificuldades (MOERBECK; ÉTHIER, 2021).

O fenômeno do estado-nação moderno fez com que a História se configurasse como disciplina escolar em inúmeros países, talvez fosse até mais simples enumerar os territórios em que não se estuda a História na escola. No entanto, o estudo da História enquanto disciplina escolar seria uma garantia de boa educação para a cidadania, de socialização para a diversidade e de instrução para o domínio desse tipo de conhecimento? Ainda que seja impossível responder a essa pergunta de uma só vez, não seria difícil afirmar que a História já foi e pode ainda vir a ser instrumentalizada para uma formação integracionista ou mesmo acrítica de saber (ÉTHIER; LEFRANÇOIS, 2019). Como fazer, então, que a disciplina escolar da História seja não um relicário de memórias gloriosas de um passado jamais vivido e sim um trampolim para se refletir sobre o mundo em que se vive?

A proposta deste pequeno ensaio é defender uma História escolar que atenda aos desafios do século XXI e que deve estar conectada a, pelo menos, algumas tendências, dentre elas: 
1) a de um diálogo perene com a produção acadêmica, seja nas suas diversas unidades temporais ou espaciais de análise, como Antiga, Medieval, Regional, Contemporânea, Global etc.; seja com as correntes da didática da História e da Educação em geral que se ocupam de refletir sobre os saberes docentes e as práticas escolares;

2) da importância de se reconhecer a escola como lócus de produção de conhecimento para que se possa avançar no que tange ao ensino e à aprendizagem. Jamais se pode esquecer que a formação de um didático da história ou de um historiador licenciado é destinada à ocupação de um lugar no chão da escola, onde a prática e a teoria têm que estar indissociavelmente entrelaçadas;

3) em um mundo cada vez menor, atravessado por dinâmicas migratórias cada vez mais sensíveis e de diversas origens e motivações, a história escolar não poderá se furtar a dialogar sobre os processos de identificação e no que se refere aos fenômenos da alteridade, ainda que o reconhecimento da diversidade não possa nos distanciar de objetivos comuns enquanto humanidade. Se há um parâmetro possível para esse fim e que pode orientar a organização curricular de forma transnacional, é aquele dos direitos humanos (UNESCO, 2015);

5) mais relevante do que determinar qual período da História é o mais importante, possivelmente um dilema infindável e mesmo infrutífero, deve-se pensar: na região onde se trabalha, nos alunos que frequentam a escola; nas questões que oprimem a livre expressão do ser humano, seja ela socioeconômica, seja de ordem cultural. Nesse sentido, desenvolver um estudo da história ancorado nas diversas realidades sociais é também tornar ele mais significativo - da História da Antiga da Índia à da Venezuela contemporânea, dos povos autóctones do atual território do Canadá aqueles da Austrália; das abadias medievais às favelas cariocas, tudo o que é humano e explica a condição humana deve interessar à História. Assim, se o que mais importa é o humano, é possível romper com pensamentos obtusos e dogmáticos sem esquecer de onde se vem, das raízes culturais, sociais, étnicas, nacionais. Como diria uma passagem do famoso samba de Paulinho da Viola, “quando penso no futuro, não esqueço o meu passado”.

Existe um compromisso ético da história escolar. O de se estudar os temas sensíveis, controversos; o de pensar que sob onda destruidora vaga das grandes guerras há os vencidos; sob os altos arranha-céus, os excluídos; sob o esquecimento de cada dia, os subalternos (FALAIZE, 2014; PEREIRA; SEFFNER, 2018). Não há mais espaço para uma História das "glórias" dos grandes homens, ainda que seja importante pensar em como cada sociedade no tempo define ao 
que é "glória", aquela que se torna imperecível ao devir do tempo, como queriam os gregos do mundo de Homero em suas guerras (VIDAL-NAQUET, 2002).

É um pouco em cada um desses elementos e nas intervenções pedagógicas que se torna possível pensar o protagonismo dos discentes nas relações de ensino-aprendizagem da História. Em particular, quando ligada aos desenvolvimentos das habilidades intelectuais do pensamento histórico é possível imaginar um quadro mais promissor para o ensino da História na escola. A classe talvez seja um lugar de uma katharsis, menos no sentido antigo da purificação e mais no da libertação intelectual - a classe como um lugar no qual se possa relativizar o passado e se distanciar de posições dogmáticas, presentistas ou retrógradas que estão enraizadas em certos domínios da memória e da História também (MARTINEAU, 1998). Afinal, ajudar a desenvolver o pensamento histórico, a consciência histórica, a capacidade narrativa dos alunos é, outrossim, uma forma de fazê-los agentes ativos em seus futuros pela compreensão do passado.

O presente dossiê é composto por catorze artigos e uma entrevista. Cada um desses trabalhos aponta em algumas das questões expostas nesse breve ensaio. A entrevista com François Audigier mostra-nos, a partir de uma profunda reflexão sobre a didática da História francófona, caminhos possíveis para a educação em História para a formação para a cidadania nesse, ainda, início de século. No Québec, Anderson Araújo-Oliveira aborda as tensões na área da didática da História após as profundas reformas no sistema escolar do Québec na década de 1960.

Os debates curriculares marcam forte presença neste dossiê. Programas escolares e resistência cultural, educação antirracista e a BNCC estão nos artigos de Marcos Antonio Batista da Silva; Danielle Pereira de Araújo, mutatis mutandis, outrossim, no trabalho de Clarice Nascimento de Melo. Nos anos iniciais do ensino de História no estado de Pernambuco, Danielle da Silva Ferreira tenta responder à dinâmica muito importante lançada pela Base Nacional Curricular Comum e os currículos escolares no âmbito estadual, enquanto Werbeth Serejo Belo pensa criticamente a organização do ensino para o mundo do trabalho.

Matheus Mendanha Cruz e Luis Fernando Cerri refletem entre as prescrições curriculares e um projeto desenvolvido para captar a recepção dos alunos. $\mathrm{O}$ mundo e as tensões advindas de fora dos muros da escola são o objeto da pesquisa de Fábio Alexandre da Silva; Lisiane Sias Manke. Do letramento digital do artigo de Nayara Silva de Carie; Ana Paula Giavara; Glauco Costa de Souza; Heli Sabino de Oliveira chegamos aos tempos de pandemia e a História do Tempo Presente na obra de Giselle Pereira Nicolau, Vivian Zampa, Sonia Maria Wanderley. 
Parte-se do ensino sobre a Roma Antiga com o trabalho de Naicon de Souza Brinco, à História Global, segundo o artigo de Alexandre Galvão Carvalho; Lucas Werlang Girardi; Carolina Ferreira de Figueiredo. Chegamos ao multiculturalismo e o ensino da História Antiga com Cleberson Henrique de Moura, Fabíola Alice dos Anjos Durães, Maria Cristina Nicolau Kormikiari, Núria Hanglei Cacete. Enfim, todos esses autores mostram a pujança atual das reflexões sobre o ensino da História Antiga para as escolas. Não menos importante, ao termo, Maria A. D. Castro e Antonieta Miguel refletem sobre a diáspora africana nos livros didáticos do ensino fundamental, enquanto Lucas Gomes de Medeiros adentra o sensível e ineludível campo das religiões afro-ameríndias no ensino da História.

E é dentro desse quadro de pluralidades temáticas, de abordagens teorias, que simbolizam a própria missão da Revista Transversos, que apresentamos ao público esse dossiê que nos ajuda a pensar um pouco sobre o futuro do passado nas escolas.

\section{Referências}

BAKOGIANNI, A. O que há de tão 'clássico' na recepção dos clássicos? Teorias, metodologias e perspectivas futuras. CODEX - Revista de Estudos Clássicos, v. 4, n. 1, p. 114-131, 30 jun. 2016.

BLOCH, M. Apologia da história: Ou o ofício do historiador. Edição: 1 ed. Rio de Janeiro: Zahar, 2002.

BOURDIEU, P. Le champ scientifique. Actes de la Recherche en Sciences Sociales, v. 2, n. 2, p. 88 104, 1976.

CARDOSO, O. The Social Flow of Historical Narratives and its many names. Esboços: histórias em contextos globais, v. 26, n. 43, p. 573-596, 11 out. 2019.

DOSSE, F. A História em migalhas: dos Annales à Nova História. Bauru: EDUSC, 2003.

ÉTHIER, M.-A.; LEFRANÇOIS, D. Jeu et l'histoire : Assassin's Creed vu par les historiens. Montréal: Del Busso Éditeur, 2021.

ÉTHIER, M.-A.; LEFRANÇOIS, D. (Org.). Mondes profanes: Enseignement, fiction et histoire. Deuxième édition revue et augmentée. Laval: Presses de l'Université Laval, 2021.

ÉTHIER, M.-A.; LEFRANÇOIS, D. L'enseignement de l'histoire à l'école, un outil d'aliénation ou d'émancipation? Timemus dominos et dona ferentes. Bulletin CREAS, v. 6, p. 83-91, 2019.

FALAIZE, B. L'enseignement des sujets controversés dans l'école française: les nouveaux fondements de l'histoire scolaire en France? Revista Tempo e Argumento, v. 6, n. 11, p. 193-223, 27 mai 2014. 
FREITAG, M. Le naufrage de l'université et autres essais d'épistémologie politique. Québec: Éditions Nota bene, 1998.

GINZBURG, C. O queijo e os vermes. São Paulo: Companhia das Letras, 2002.

KOSELLECK, R. Futuro passado: contribuição à semântica dos tempos históricos. Rio de Janeiro (RJ): Pontifícia Universidade Católica do Rio de Janeiro, 2006.

LEITE, P. G. O Ensino de História Antiga no Brasil: Percepções a partir das propostas da BNCC. In: NETO, J. M. G. DE S.; MOERBECK, G.; BIRRO, R. M. Antigas Leituras: ensino de História. Recife/Rio de Janeiro: EDUPE/Autografia, 2020. p. 93-113.

MARTINEAU, R. "La réforme du curriculum : quelle histoire et quelle formation pour quelle citoyenneté?». Traces, 1. v. 38, p. 38-47, jan. 1998.

MOERBECK, G. Em defesa do ensino da História Antiga nas escolas contemporâneas: Base Nacional Curricular Comum, usos do passado e pedagogia decolonial. v. 1, n. 21, p. 50-91, 2021.

MOERBECK, G.; ÉTHIER, M.-A. Os desafios da educação para a cidadania e do ensino da História na escola: uma entrevista com François Audigier. Revista Transversos. Dossiê: $\mathrm{O}$ futuro do passado: Desafios para o Ensino da História nas escolas numa perspectiva global. Rio de Janeiro, $n^{\circ} .23,2021$.

MOERBECK, G. História Antiga no ensino fundamental: Um estudo sobre os mitos gregos antigos e a consciência histórica. Revista História Hoje, v. 7, n. 13, p. 225-247, 26 nov. 2018.

NETO, J. M. G. DE S. O ensino de História e o infinito banco de imagens: Exxodo, Deuses e Reis (2014). Outros Tempos - Pesquisa em Foco - História, v. 16, n. 28, p. 162-183, 2019.

PEREIRA, N. M.; SEFFNER, F. Ensino de História: passados vivos e educação em questões sensíveis. Revista História Hoje, v. 7, n. 13, p. 14-33, 26 nov. 2018.

RICOEUR, P. Mémoire, l'histoire, l'oubli. Paris: Seuil, 2000.

RÜSEN, J. Historische Sinnbildung: Grundlagen, Formen, Entwicklungen. Wiesbaden: Springer Fachmedien Wiesbaden, 2020.

RÜSEN, J. ¿Qué es la cultura histórica?: Reflexiones sobre una nueva manera de abordar la historia.

UNESCO (Org.). Rethinking education: towards a global common good? Paris: UNESCO Publishing, 2015.

VIDAL-NAQUET, P. O Mundo de Homero. São Paulo: Companhia das Letras, 2002.

WANDERLEY, S. O entrelugar do aprendizado escolar de História: uma perspectiva de História Pública. Revista História Hoje, v. 9, n. 18, p. 125-144, 23 dez. 2020.

\section{Sobre os Editores}


Guilherme Moerbeck: professor Adjunto da área Teoria, Historiografia e Ensino de História da Universidade do Estado do Rio de Janeiro, bem como do ProfHistória e PPGH ambos na UERJ. É Licenciado em História (2004); mestre (2007) e doutor (2013) em História Antiga pela Universidade Federal Fluminense (UFF). Possui pós-doutorado em Ensino de História na FGVRio (2015); em Arqueologia Clássica no Museu de Arqueologia e Etnologia (USP - 2019) e em Educação na Université du Québec à Montréal (UQÀM - 2021). Teve passagens como colaborador em pesquisa arqueológica em Delos organizada no âmbito da École française d'Athènes (EfA); Visiting research fellow no Departamento de Estudos Clássicos da Brown University, assim como pesquisador associado nas Faculdades de Educação da Université de Montréal - UdeM e da UQÀM. Coordena o Didaskō - Grupo de Estudos em Ensino da História Antiga - LEDDES/UERJ. Além disso, colabora em pesquisas nos: CRIFPE - Centre de recherche interuniversitaire sur la formation et la profession enseignante (UQÀM); LABECA Laboratório de Estudos sobre a Cidade Antiga - MAE/USP; na COMUM - Comunidade de Estudos da Teoria da História - UERJ e no LAHUD - Laboratório em Rede de Humanidades Digitais (IBICT). Trabalhou durante 14 anos no ensino fundamental e foi destaque no Prêmio Professores do Brasil em 2018. É autor de artigos na área de Ensino de História; Educação; História Antiga e Teoria da História e dos livros Guerra, Política e Tragédia na Grécia Clássica (2014); Entre a Religião e a Política: Eurípides e a Guerra do Peloponeso (2017); um dos organizadores do Antigas Leituras: Ensino de História (2020).

Marc-André Éthier: formado em História (bacharelado e mestrado, Université de Montréal . UdeM) e em Didática (doutorado em Didática, UdeM). Ensinou história no ensino médio, foi professor na Université du Québec à Trois-Rivières e, desde 2004, é professor na UdeM. É membro de diversos grupos de pesquisa, entre os quais o DiSEC (Diversité scolaire et l'éducation à la citoyenneté) e o CRIFPE (Centre de recherche interuniversitaire sur la formation et la profession enseignante). É também presidente do Comité d'agrément des programmes de formation à l'enseignement (CAPFE). As suas pesquisas foram financiadas pelo FRQSC e pelo CRSH. Estas pesquisas incidiram sobre a análise de conteúdo dos programas e dos manuais de história. Há alguns anos, elas incidem sobre o uso que os professores e os alunos fazem dos meios didáticos, como os manuais, os romances, os longas-metragens de ficção, os jogos de videogames de história ou nos artefatos e arquivos, bem como sobre as aprendizagens dos alunos em história e, em particular, sobre as que dizem respeito aos procedimentos de pesquisa em história. Marc-André Éthier é ainda o editor-chefe da Revue des sciences de l'éducation.

David Lefrançois: Professor de fundamentos da Educação na Université du Québec en Outaouais UQO desde 2008. Suas pesquisas e publicações analisam os discursos dos currículos nas disciplinas do universo social (história, geografia, mundo contemporâneo, educação financeira), os métodos e meios de ensino e de avaliação da aprendizagem do pensamento histórico no ensino primário e secundário. É Coordenador da Equipe de Investigação sobre a Diversité scolaire et l'éducation citoyenne (DiSEC) e membro da Partenariat de recherche sur l'Accès au droit et à la justice (ADAJ), trabalha sobre os usos feitos na sala de aula do material didático e sobre os usos mais eficazes que seria possível fazer da história profana. Promove abordagens à prática política e cívica baseadas na ética do discurso. 


\section{Como citar:}

MOERBECK, Guilherme; ÉTHIER, Marc-André; LEFRANÇOIS, David. O futuro do passado: Desafios para o Ensino da História nas escolas numa perspectiva global. In: Revista Transversos. Rio de Janeiro, no. 23, 2021. pp. 7-14. Disponível em: <https://www.epublicacoes.uerj.br/index.php/transversos/article/view/64228/40497>. ISSN 2179-7528. DOI: $10.12957 /$ transversos.2021.64228 